\title{
Improving Teacher Professional Development Through Lesson Study
}

\author{
Toshiakira Fujii and Akihiko Takahashi
}

\section{Discussion}

The purpose of this proposed Discussion Group is to facilitate discussion and initiate collaborative research with colleagues around the world to seek effective ways to improve teacher professional development through Lesson Study.

Each session, Session 1 (Tuesday, July 10) and Session 2 (Saturday, July 14) was began by two of four key questions addressed by the panel. Then the panelists and the participants had fruitful discussion around the key questions.

Session 1 (Tuesday, July 10).

Key Questions

- What are the key elements of Lesson Study that can help teachers gain mathematical knowledge for teaching?

- What are the key elements of Lesson Study that can help teachers develop expertise in teaching mathematics effectively?

Chair: Toshiakira Fujii (Japan); Discussant: Susie Groves (Australia); Panel: Jennifer Lewis (USA), Yoshinori Shimizu (Japan), Akihiko Takahashi (USA),Tad Watanabe (USA), Nobuki Watanabe (Japan); Reporter: Yo-An Lee (Korea).

Session 2 (Saturday, July 14).

Organizers Co-chairs: Toshiakira Fujii (Japan), Akihiko Takahashi (USA); Team Members: Susie Groves (Australia), Yo-An Lee (Korea); Liaison IPC Member: Mercy Kazima (Malawi).

T. Fujii (ه)

Tokyo Gakugei University, Tokyo, Japan

e-mail: tfujii@u-gakugei.ac.jp

A. Takahashi

DePaul University, Chicago, USA

e-mail: atakahas@depaul.edu

(C) The Author(s) 2015

609

S.J. Cho (ed.), The Proceedings of the 12th International Congress

on Mathematical Education, DOI 10.1007/978-3-319-12688-3_69 


\section{Key Questions}

- How can an established effective professional development model such as Lesson Study be translated for use in different cultures?

- How can a professional development model such as Lesson Study be adapted for use in pre-service teacher education?

Chair: Akihiko Takahashi (USA); Discussant: Lim Chap Sam (Malaysia); Panel: Koichi Nakamura, (Japan), Anika Dreher (Germany), Don Gilmore (USA), Berinderjeet Kaur (Singapore), Thomas E. Ricks (USA); Reporter: Yo-An Lee (Korea).

\section{Results}

As the result of two-day discussion the following questions are raised by the discussion group for further discussion:

Question 1: Although we recognize the roles of lesson study facilitators/leaders/ outside experts are important, what does expertise mean in conducting lesson study is still not entirely clear.

Outside experts can push LS members in terms of (1) content knowledge (what kinds of knowledge is needed at each particular teaching episode), (2) pedagogical knowledge (how to help students with particular contents), and (3) interactional (whether LS groups are mature enough to take and produce criticism).

In Japan, university in-service training can link to school practices where expertise come into play. In-service training, there are multiple levels. Notable is that LS study groups often have expert among themselves who can handle some aspects of lesson study. In general, it is hard to find a capable expert.

Question 2: Although lesson study is a form of professional development based on collaboration, sometimes teachers feel uncomfortable when criticized by their colleagues.

American teachers are not familiar with or comfortable with criticizing. You want to criticize lesson, not teaching. This could be an effective way of handling the pressure of giver and taker of criticism. One way to handle the pressure is to have groups work on lesson plans and choose one person to teach at the last minute. Lesson study helps teachers work together and to see what kids are doing. Lesson study should try to move their focus from "what I did wrong" to "what the issues were" "what students did (not) learn?"

Question 3: May be good idea to explore more about authentic school based lesson study in Japan.

What students should learn may be clearer in Japan. Developing school research theme might be a good starting point for group of teachers. (Theme means "what do you want to do in the class"). Although novice teachers don't know how to anticipate student responses, they learn how to anticipate student responses through school-based lesson study. 
Open Access This chapter is distributed under the terms of the Creative Commons Attribution Noncommercial License, which permits any noncommercial use, distribution, and reproduction in any medium, provided the original author(s) and source are credited. 